\title{
Extraction optimization and antioxidant activity of Phyllanthus urinaria polysaccharides
}

\author{
Yong LIU ${ }^{1 *}$ (D), Sui-Min LI ${ }^{1}$
}

\begin{abstract}
Three extraction parameters including extraction time, material to solvent ratio, and extraction temperature for the extraction yield of Phyllanthus urinaria polysaccharides were optimized by response surface methodology. The results revealed that the optimal extraction process was extraction time of $5.3 \mathrm{~h}$, extraction temperature of $93^{\circ} \mathrm{C}$, and material to solvent ratio of $1: 47 \mathrm{~g} / \mathrm{mL}$, under which the polysaccharide yield was 6.40\%; The three parameters had significant effect on the polysaccharide yield, and the influence of extraction time was the greatest and that of extraction temperature was the lowest. The antioxidant activity test indicated that the equivalent scavenging ability of Phyllanthus urinaria polysaccharides on DPPH and ABTS free radicals was 0.88 and $0.84 \mu \mathrm{g} \mathrm{TBHQ} / \mu \mathrm{g}$ of polysaccharides, respectively; while the reducing power and total antioxidant capacity of Phyllanthus urinaria polysaccharides was equivalent to $93.62 \%$ and $93.55 \%$ of TBHQ, respectively. The Phyllanthus urinaria polysaccharides had good antioxidant activity.
\end{abstract}

Keywords: Phyllanthus urinaria; polysaccharides; antioxidant activity; response surface methodology.

Practical Application: The optimal extraction conditions for Phyllanthus urinaria polysaccharides are desirable and practical, and the extracted polysaccharides can be used as a promising nutraceutical and food ingredient.

\section{Introduction}

Active oxygen free radicals are intermediate metabolites produced in life activities (Tahmouzi \& Ghodsi, 2014). Excessive reactive oxygen free radicals can cause damage to macromolecular substances in organisms, induce various diseases, accelerate the aging of body, and thus seriously affect human health (Al-Reza et al., 2016; Han et al., 2019; Mo et al., 2017; Ru et al., 2019). In order to reduce the damage of active oxygen radicals, antioxidants are commonly used. At present, there are two main types of antioxidants, one is synthetic and the other is natural. Synthetic antioxidants have limited therapeutic effects due to their significant toxicity, so the search for safe and effective natural antioxidants from natural resources is receiving more and more attention (Carocho et al., 2018). Many studies have shown that the natural polysaccharides isolated from plants have a good antioxidant activity (Chen et al., 2019a; Zhao et al., 2019), which can effectively scavenge free radicals in organisms and have a good health care effect (Chen et al., 2014). Therefore, it is of great significance to develop them into a new type of natural antioxidant.

Phyllanthus urinaria is an annual herbaceous plant of the genus Euphorbiaceae, which is widely distributed in tropical and subtropical countries (Liu et al., 2018, 2019). Historically, Phyllanthus urinaria is used as a folk medicine for its good biological activities such as antiviral, antioxidant, anti-inflammatory, and antimicrobial activities (Hau et al., 2009; Lin et al., 2008). Phyllanthus urinaria contains a variety of active ingredients, mainly including lignans, tannins, flavonoids, phenolics, and terpenoids (Geethangili \& Ding,
2018; Mediani et al., 2015). At present, the research of Phyllanthus urinaria is mainly focused on the extraction of bioactive substances (Liu et al., 2018), the microencapsulation of bioactive substances (Lam et al., 2013; Liu et al., 2019), and the study of antiviral, antitumor, hepatoprotective, antidiabetic, antioxidative, antihypertensive, thrombolytic and antimicrobial effects of phenolic compounds (Du et al., 2018; Geethangili \& Ding, 2018). In recent years, functional polysaccharides have become a research hotspot due to their good biological activity (Jiang et al., 2019). Phyllanthus urinaria is rich in polysaccharides, however, little is known about the extraction optimization and antioxidant activity of Phyllanthus urinaria polysaccharides.

In this paper, three parameters for the extraction of Phyllanthus urinaria polysaccharides were optimized for the highest polysaccharide yield by response surface methodology (RSM), and its antioxidant activity was also evaluated. The aim was to provide a theoretical basis for the extraction of Phyllanthus urinaria polysaccharides and its development and utilization in the field of food and medicine.

\section{Experimental}

\subsection{Chemicals}

Ferric chloride, glucose, phenol, DPPH, tert-butylhydroquinone (TBHQ), trichloroacetic acid, ABTS, ammonium molybdate, sodium phosphate, and potassium ferricyanide were bought from Shanghai Macklin Co. Ltd. 


\subsection{Extraction of Phyllanthus urinaria polysaccharides}

Phyllanthus urinaria was dried $\left(50^{\circ} \mathrm{C}, 48 \mathrm{~h}\right)$, pulverized into powder and passed through a 100 -mesh sieve. The resulting powder was subjected to extract Phyllanthus urinaria polysaccharides at different extraction time, material to solvent ratio and extraction temperature. After the extraction was completed, the extracted slurry was centrifuged (12000 rpm, $15 \mathrm{~min}$ ), and the polysaccharide content of the resulting supernatant was measured by the phenol-sulfuric acid method using glucose as a standard (DuBois et al., 1956). The polysaccharide yield of Phyllanthus urinaria was determined as following (Equation 1):

Yield $(\%)=\frac{V \times C}{M} \times 100$

where $V$ was the supernatant volume $(\mathrm{mL})$; $C$ was the polysaccharide content $(\mathrm{mg} / \mathrm{mL})$ obtained from the glucose standard curve; and $M$ was the weight (mg) of powder.

\subsection{Extraction optimization design}

Based on the evaluation of the effects of extraction parameters on the polysaccharide yield by single-factor experiment, a Box-Behnken design was used to optimize the extraction parameters of extraction time $(A, 4-6 \mathrm{~h})$, extraction temperature $\left(B, 80-100^{\circ} \mathrm{C}\right)$ and material to solvent ratio $(C, 1: 40-1: 60 \mathrm{~g} / \mathrm{mL})$ on the polysaccharide yield $(Y, \%)$ by the Design-Expert software. The Box-Behnken design and results were shown in Table 1.

\subsection{Antioxidant activity test}

The polysaccharide supernatant obtained under the optimal extraction process was concentrated to a third volume at $50{ }^{\circ} \mathrm{C}$ and then subjected to remove proteins using Sevag reagent. Then, the polysaccharides were precipitated by adding 4 -fold volume of absolute ethanol at $4{ }^{\circ} \mathrm{C}$ for $24 \mathrm{~h}$. The precipitates were collected by centrifugation at $5000 \mathrm{rpm}$ for $20 \mathrm{~min}$ and then

Table 1. Box-Behnken design and test results.

\begin{tabular}{ccccc}
\hline \multirow{2}{*}{ Run } & \multicolumn{3}{c}{ Independent variables } & $Y(\%)$ \\
\cline { 2 - 4 } & $A(\mathrm{~h})$ & $B\left({ }^{\circ} \mathrm{C}\right)$ & $C(\mathrm{~g} / \mathrm{mL})$ & \\
\hline 1 & $4(-1)$ & $90(0)$ & $1: 60(1)$ & 4.98 \\
2 & $6(1)$ & $90(0)$ & $1: 40(-1)$ & 5.97 \\
3 & $5(0)$ & $80(-1)$ & $1: 60(1)$ & 5.46 \\
4 & $5(0)$ & $90(0)$ & $1: 50(0)$ & 6.38 \\
5 & $6(1)$ & $90(0)$ & $1: 60(1)$ & 5.82 \\
6 & $5(0)$ & $100(1)$ & $1: 60(1)$ & 5.39 \\
7 & $5(0)$ & $100(1)$ & $1: 40(-1)$ & 6.15 \\
8 & $6(1)$ & $100(1)$ & $1: 50(0)$ & 6.01 \\
9 & $5(0)$ & $90(0)$ & $1: 50(0)$ & 6.31 \\
10 & $5(0)$ & $80(-1)$ & $1: 40(-1)$ & 5.49 \\
11 & $5(0)$ & $90(0)$ & $1: 50(0)$ & 6.35 \\
12 & $4(-1)$ & $90(0)$ & $1: 40(-1)$ & 5.46 \\
13 & $4(-1)$ & $100(1)$ & $1: 50(0)$ & 5.49 \\
14 & $4(-1)$ & $80(-1)$ & $1: 50(0)$ & 5.23 \\
15 & $6(1)$ & $80(-1)$ & $1: 50(0)$ & 5.61 \\
\hline
\end{tabular}

Notes: extraction time $(A)$, extraction temperature $(B)$, material to solvent ratio $(C)$ and polysaccharide yield $(Y)$. dialyzed against deionized water at $4{ }^{\circ} \mathrm{C}$ for $48 \mathrm{~h}$, and followed by lyophilization to achieve the powder of Phyllanthus urinaria polysaccharides. The powder was dissolved to prepare various concentrations of polysaccharide solution for the antioxidant activity test using TBHQ as a control. The reducing power (RP), ABTS, and DPPH assays were performed by the method of Liu et al. (2018). The total antioxidant capacity (TOAC) was also measured according to Zhang et al. (2014).

\subsection{Statistical analysis}

All the test was conducted in triplicate. Design-Expert software was used to design, analyze, and optimize the extraction yield of Phyllanthus urinaria polysaccharides. A p-value less than 0.05 was significant difference.

\section{Results and discussion}

\subsection{Single-factor test analysis}

Effect of extraction time on polysaccharide yield

It can be seen from Figure 1A that when the extraction time increased, the polysaccharide yield increased and reached a maximum at $4 \mathrm{~h}$, but decreased after $4 \mathrm{~h}$. This is because the increase in extraction time makes it easier and faster to dissolve the polysaccharides into the solvent (Lin et al., 2017), but too long extraction time will result in the destruction of polysaccharide
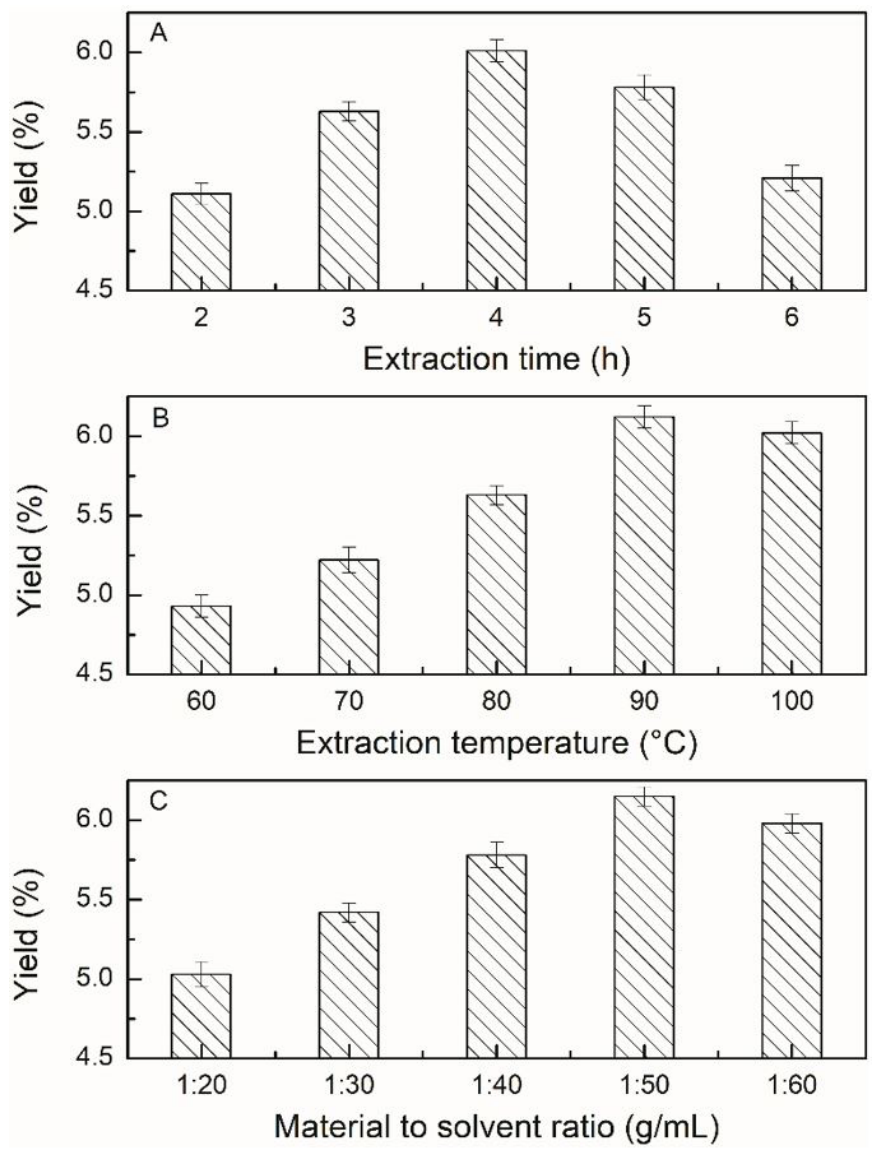

Figure 1. Effect of (A) extraction time, (B) extraction temperature and (C) material to solvent ratio on polysaccharide yield. 
structure (Chen et al., 2019b; Zheng et al., 2019) and competitive dissolution of other impurities (Nuerxiati et al., 2019), leading in a decrease in yield. This phenomenon was consistent with the extraction of polysaccharides in other literatures (Wang et al., 2018b; Yang et al., 2017). Therefore, the extraction time should be chosen around $4 \mathrm{~h}$.

\section{Effect of extraction temperature on polysaccharide yield}

As shown in Figure 1B, with the increase of extraction temperature from 60 to $90^{\circ} \mathrm{C}$, the polysaccharide yield increased and reached a maximum at $90^{\circ} \mathrm{C}$, but decreased over $90^{\circ} \mathrm{C}$. As the extraction temperature continues to increase, the diffusion coefficient of polysaccharides increases, and consequently the content of polysaccharides in the aqueous solution increases. However, excessive temperature can cause the hydrolyzation or degradation of polysaccharides (Hu et al., 2018; Li et al., 2019; Lin et al., 2017), resulting in a decrease in polysaccharide yield and an increase in energy consumption. This trend was in correspondence with the reports of polysaccharide extraction by other authors (Xu et al., 2019; Zhang et al., 2017). Therefore, the extraction temperature should be around $90^{\circ} \mathrm{C}$.

\section{Effect of material to solvent ratio on polysaccharide yield}

As can be observed in Figure 1C, when material to solvent ratio increased in the range of 1:20 to $1: 60 \mathrm{~g} / \mathrm{mL}$, the polysaccharide yield had a maximum at 1:50 $\mathrm{g} / \mathrm{mL}$. When the amount of material to solvent ratio is low, the polysaccharides in the powder cannot be completely transferred to the solvent, resulting in an incomplete extraction and the low polysaccharide yield. Increasing material to solvent ratio can cause a greater concentration difference between the internal plant cells and the external solvent, which can be beneficial for the rapid diffusion of polysaccharides (Ying et al., 2011); however, too large material to solvent ratio can also cause other impurities in the powder to competitively diffuse and dissolve with the polysaccharides, resulting in a decrease in the polysaccharide yield. Therefore, the material to solvent ratio should be around $1: 50 \mathrm{~g} / \mathrm{mL}$.

\subsection{Extraction optimization of polysaccharide yield}

According to the single-factor test analysis and the Box-Benhnken design principle, taking extraction time $(A, \mathrm{~h})$, extraction temperature $\left(B,{ }^{\circ} \mathrm{C}\right)$ and material to solvent ratio $(C, \mathrm{~g} / \mathrm{mL})$ as independent variables and polysaccharide yield $(Y, \%)$ as response value, RSM was used to analyze the three parameters and investigate the significance of each parameter on the polysaccharide yield and the optimal combination of various parameters.

\section{Establishment of fitted model and analysis of variance}

The statistical analysis software (Design-Expert 8.05) was used to perform the fitting analysis of regression model on the data in Table 1. A quadratic response surface regression model was established, and the quadratic multiple regression equation for the polysaccharide yield was obtained as follows (Equation 2):
$Y=6.35+0.28 A+0.16 B-0.18 C+0.035 A B+$

$0.083 A C-0.18 B C-0.41 A^{2}-0.35 B^{2}-0.38 C^{2}$

In order to verify the feasibility of the regression equation for the extraction process of Phyllanthus urinaria polysaccharides, the variance analysis and the significance test were performed on the regression model. The results were presented in Table 2. As shown in Table 2, the p-value of the regression model was less than 0.01 , showing the regression model was extremely significant; the p-value of the lack-of-fit was $0.1148>0.05$, indicating the loss was not significant; the correlation coefficient of the model was $\mathrm{R}^{2}=0.9881$, which revealed that $98.81 \%$ of the test data can be explained by this regression equation, and can better reflect the change of the polysaccharide yield; the adjustment correlation coefficient of the model was $R 2$ adj $=0.9668$, which considered that the model was reliable and had high credibility. In summary, the regression model had a good fitting with the test data, and the test error was small. Therefore, the model can be used to predict and analyze the extraction parameters of Phyllanthus urinaria polysaccharides.

The results of variance analysis of the regression model in Table 2 revealed that the p-values of extraction time $(A)$, extraction temperature $(B)$ and material to solvent ratio $(C)$, the interaction between $B$ and $C$, and the quadratic terms of $A^{2}, B^{2}$ and $C^{2}$ were less than 0.01 , which indicated that they had an extremely significant effect on the polysaccharide yield. However, the others were all more than 0.05 , showing there was no significant influence. It can be concluded from the p-values that the influence of extraction time on the polysaccharide yield was the greatest and that of extraction temperature was the lowest.

\section{Response surface analysis}

The response surface plots of the regression model were shown in Figure 2. According to the design principle and analysis of the response surface experiment, the greater the curvature of three-dimensional response surface diagrams, the more obvious the difference between the two parameters was, which

Table 2. Analysis of variance for Box-Behnken test.

\begin{tabular}{ccclcc}
\hline Source & Sum of squares & $\begin{array}{c}\text { Degree } \\
\text { of } \\
\text { freedom }\end{array}$ & $\begin{array}{c}\text { Mean } \\
\text { square }\end{array}$ & $F$-value & $p$-value \\
\hline Model & 2.63 & 9 & 2.63 & 46.32 & 0.0003 \\
$A$ & 0.63 & 1 & 0.63 & 100.15 & 0.0002 \\
$B$ & 0.20 & 1 & 0.20 & 30.91 & 0.0026 \\
$C$ & 0.25 & 1 & 0.25 & 39.89 & 0.0015 \\
$A B$ & 0.0049 & 1 & 0.0049 & 0.78 & 0.4188 \\
$A C$ & 0.027 & 1 & 0.027 & 4.31 & 0.0926 \\
$B C$ & 0.13 & 1 & 0.13 & 21.09 & 0.0059 \\
$A^{2}$ & 0.63 & 1 & 0.63 & 99.84 & 0.0002 \\
$B^{2}$ & 0.45 & 1 & 0.45 & 70.91 & 0.0004 \\
$C^{2}$ & 0.52 & 1 & 0.52 & 82.54 & 0.0003 \\
Residual & 0.032 & 5 & 0.0063 & & \\
Lack of fit & 0.029 & 3 & 0.0097 & 7.87 & 0.1148 \\
Pure error & 0.0025 & 2 & 0.0012 & & \\
Cor. total & 2.67 & 14 & & & \\
$R^{2}=0.9881$ & $R 2$ adj=0.9668 & & & & \\
\hline
\end{tabular}



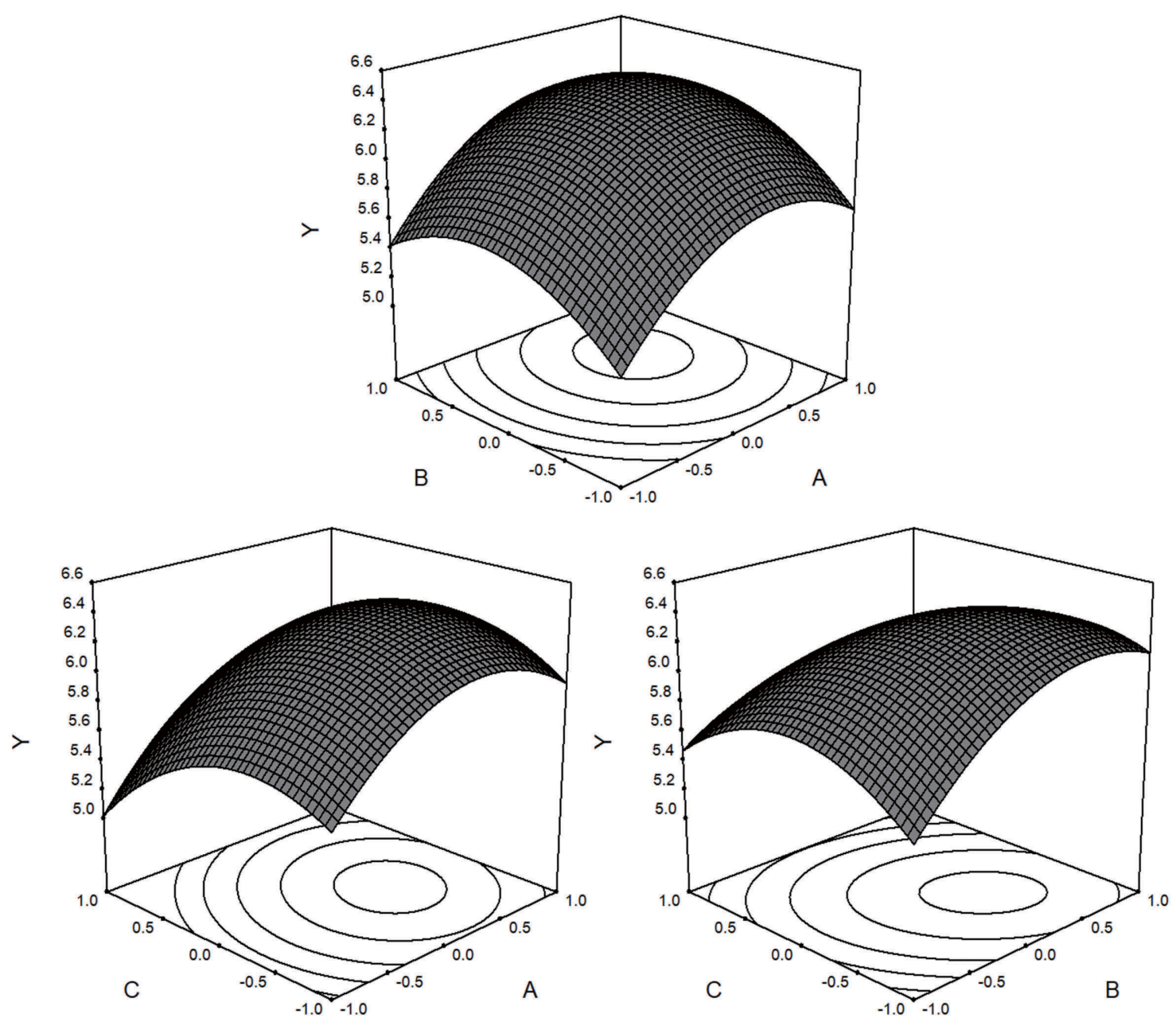

Figure 2. Plots of contours and response surfaces for extraction time $(A)$, extraction temperature $(B)$ and material to solvent ratio $(C)$ on polysaccharide yield $(Y)$.

can effectively reflect the interaction between the parameters on the polysaccharide yield. It can be observed in Figure 2 that the influence of interaction between extraction temperature $(B)$ and material to solvent ratio $(C)$ was significant, but that of other interaction was not significant.

\section{Verification of optimal extraction process}

It can be seen from Figure 2 that the three three-dimensional response surface diagrams had the highest points, and the polysaccharide yield $(Y)$ increased first and then decreased with the increase of extraction time $(A)$, extraction temperature $(B)$ and material to solvent ratio $(C)$, indicating that there must be an optimal extraction process for the highest polysaccharide yield. By solving the model equation, the optimal extraction process of Phyllanthus urinaria polysaccharides was: extraction time of $5.3 \mathrm{~h}$, extraction temperature of $93^{\circ} \mathrm{C}$ and material to solvent ratio of $1: 47 \mathrm{~g} / \mathrm{mL}$. Under this process, the polysaccharide yield was $6.40 \%$, which was $0.62 \%$ relative error with the predicted yield (6.44\%). The results indicated that the established model can effectively and reliably explain the impact of various parameters on the polysaccharide yield.

\subsection{Antioxidant activity analysis}

The ability of Phyllanthus urinaria polysaccharides to scavenge free radicals of DPPH and ABTS presented in Figure 3A and 3B showed that the polysaccharides had good scavenging ability to DPPH and ABTS free radicals. As sample concentration increased, the scavenging effect of the polysaccharides increased linearly. The scavenging effect of the polysaccharides on DPPH and ABTS free radicals was slightly lower than that of TBHQ. The $\mathrm{IC}_{50}$ of polysaccharides for scavenging DPPH and ABTS free radicals was $6.54 \mu \mathrm{g} / \mathrm{mL}$ and $114.13 \mu \mathrm{g} / \mathrm{mL}$, respectively; correspondingly, that of TBHQ was $5.78 \mu \mathrm{g} / \mathrm{mL}$ and $95.30 \mu \mathrm{g} / \mathrm{mL}$, respectively. It can be concluded from their $\mathrm{IC}_{50}$ that the equivalent scavenging ability of the polysaccharides on DPPH and ABTS free radicals can be expressed as 0.88 and $0.84 \mu \mathrm{g} \mathrm{TBHQ} / \mu \mathrm{g}$ of polysaccharides, respectively. In comparison with the IC50 of other polysaccharides, the ability of Phyllanthus urinaria polysaccharides to scavenge DPPH free radicals was close to that of Rosa roxburghii Tratt. Polysaccharides $(8.38 \mu \mathrm{g} / \mathrm{mL}$ ) (Wang et al., 2018a), but higher than that of Chestnut rose polysaccharides $(100 \mu \mathrm{g} / \mathrm{mL})($ Chen \& Kan, 2018) and Lentinus edodes polysaccharides from tobacco waste $(560 \mu \mathrm{g} / \mathrm{mL})$ (Lin et al., 2019); the ability of Phyllanthus urinaria polysaccharides to scavenge ABTS free radicals was higher 

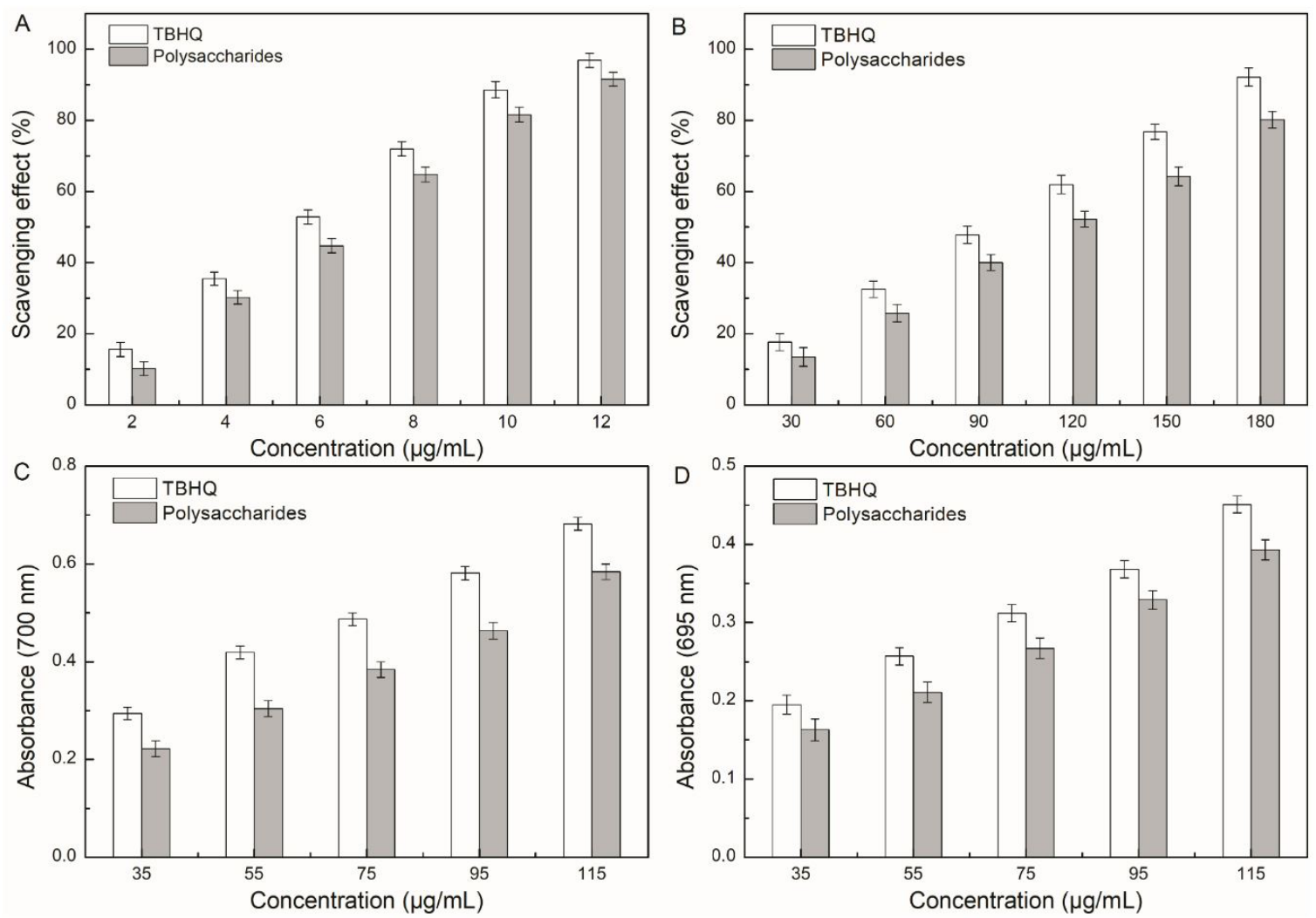

Figure 3. Scavenging effect of polysaccharides and TBHQ on DPPH (A) and ABTS free radicals (B); reducing power (C) and total antioxidant capacity (D) of polysaccharides and TBHQ.

than that of Chimonobambusa quadrangularis Polysaccharides $(452 \mu \mathrm{g} / \mathrm{mL})$ (Chen et al., 2019a) and Kiwifruit Polysaccharides $(1980 \mu \mathrm{g} / \mathrm{mL})$ (Han et al., 2019), but lower than that of Pouteria campechiana seed Polysaccharides $(29.9 \mu \mathrm{g} / \mathrm{mL}$ ) (Ma et al., 2020).

According to the experimental principle of RP and TAOC, the larger an absorbance was, the greater RP and TAOC were. Figure $3 \mathrm{C}$ and $3 \mathrm{D}$ showed that the absorbance had a linear increase with increasing sample concentration, and the absorbance of TBHQ was slightly higher than that of polysaccharides. The linear regression equations of the polysaccharides for RP and TAOC were $\mathrm{y}=0.0044 \mathrm{x}+0.0603\left(\mathrm{R}^{2}=0.9818\right), \mathrm{y}=0.0029 \mathrm{x}$ $+0.0059\left(R^{2}=0.9882\right)$, respectively; correspondingly, those of TBHQ were $\mathrm{y}=0.0047 \mathrm{x}+0.1409\left(\mathrm{R}^{2}=0.9933\right), \mathrm{y}=0.0031 \mathrm{x}$ $+0.083\left(R^{2}=0.9915\right)$, respectively. According to the slopes of the regression equations, it can be calculated that the RP and TAOC of the polysaccharides were equivalent to $93.62 \%$ and $93.55 \%$ of TBHQ, respectively. Compared with other polysaccharides, the RP of Phyllanthus urinaria polysaccharides (absorption of 0.463 at $95 \mu \mathrm{g} / \mathrm{mL}$ ) was higher than that of litchi polysaccharides (absorption of 0.320 at $1000 \mu \mathrm{g} / \mathrm{mL}$ ) (Gao et al., 2017) and polysaccharides from tobacco waste (absorption of 0.377 at $1000 \mu \mathrm{g} / \mathrm{mL}$ ) (Jing et al., 2016); meanwhile, the TAOC of Phyllanthus urinaria polysaccharides (absorption of 0.451 at $115 \mu \mathrm{g} / \mathrm{mL}$ ) was higher than that of Trapa quadrispinosa polysaccharides (absorption of 0.510 at $400 \mu \mathrm{g} / \mathrm{mL}$ ) (Raza et al. 2017).
In general, Phyllanthus urinaria polysaccharides possessed good antioxidant activity by the comparison with the control (TBHQ) and other polysaccharides. It was reported that the molecular mass, uronic acid content, and monosaccharide composition of polysaccharides are related to their antioxidant capacity (Wang et al., 2016). So, the antioxidant activity of Phyllanthus urinaria polysaccharides was affected not by only one factor but by the combination of multiple factors (Shang et al., 2019).

\section{Conclusions}

The extraction parameters, including extraction time, material to solvent ratio and extraction temperature, for the extraction of Phyllanthus urinaria polysaccharides were optimized by RSM. The optimal extraction process was: extraction time of $5.3 \mathrm{~h}$, extraction temperature of $93^{\circ} \mathrm{C}$, and material to solvent ratio of $1: 47 \mathrm{~g} / \mathrm{mL}$, under which the polysaccharide yield $(6.40 \%)$ was basically consistent with the predicted yield (6.44\%). The antioxidant activity test showed that the polysaccharides had the strong ability to scavenge DPPH and ABTS free radicals, and had good reducing power and total antioxidant capacity.

\section{Acknowledgements}

This work was financially supported by Characteristic Innovation Project of Education Department of Guangdong Province (No. 2014KTSCX192) and Science and Technology Project of Zhaoqing City (No. 2014F012). 


\section{References}

Al-Reza, S. M., Rokonuzzaman, M., Afroz, M., Hussain, M. I., Rashid, M. A., \& Rahman, A. (2016). Chemical composition and antioxidant activity of essential oil and organic extracts of premna integrifolia linn. Brazilian Archives of Biology and Technology, 59(0), e16160223. http://dx.doi.org/10.1590/1678-4324-2016160223.

Carocho, M., Morales, P., \& Ferreira, I. C. F. R. (2018). Antioxidants: Reviewing the chemistry, food applications, legislation and role as preservatives. Trends in Food Science \& Technology, 71, 107-120. http://dx.doi.org/10.1016/j.tifs.2017.11.008.

Chen, G., \& Kan, J. (2018). Ultrasound-assisted extraction, characterization, and antioxidant activity in vitro and in vivo of polysaccharides from Chestnut rose (Rosa roxburghii tratt) fruit. Journal of Food Science and Technology, 55(3), 1083-1092. http://dx.doi.org/10.1007/s13197017-3023-8. PMid:29487451.

Chen, G., Fang, C., Ran, C., Tan, Y., Yu, Q., \& Kan, J. (2019a). Comparison of different extraction methods for polysaccharides from bamboo shoots (Chimonobambusa quadrangularis) processing byproducts. International Journal of Biological Macromolecules, 130, 903-914. http://dx.doi.org/10.1016/j.ijbiomac.2019.03.038. PMid:30849468.

Chen, W., Jia, Z., Zhu, J., Zou, Y., Huang, G., \& Hong, Y. (2019b). Optimization of ultrasonic-assisted enzymatic extraction of polysaccharides from thick-shell mussel (Mytilus coruscus) and their antioxidant activities. International Journal of Biological Macromolecules, 140, 1116-1125. http://dx.doi.org/10.1016/j.ijbiomac.2019.08.136. PMid:31425762.

Chen, Y., Xiong, W., Zeng, L., Wang, Y., Zhang, S., Xu, M., Song, M., Wang, Y., Du, H., Liu, J., Wang, D., Wu, Y., \& Hu, Y. (2014). Bush Sophora Root polysaccharide and its sulfate can scavenge free radicals resulted from duck virus hepatitis. International Journal of Biological Macromolecules, 66, 186-193. http://dx.doi.org/10.1016/j. ijbiomac.2014.02.038. PMid:24582875.

Du, G., Xiao, M., Yu, S., Wang, M., Xie, Y., \& Sang, S. (2018). Phyllanthus urinaria: a potential phytopharmacological source of natural medicine. International Journal of Clinical and Experimental Medicine, 11(7), 6509-6520.

DuBois, M., Gilles, K. A., Hamilton, J. K., Rebers, P. A., \& Smith, F. (1956). Colorimetric method for determination of sugars and related substances. Analytical Chemistry, 28(3), 350-356. http://dx.doi. org/10.1021/ac60111a017.

Gao, W., Lin, P., Zeng, X. A., \& Brennan, M. A. (2017). Preparation, characterisation and antioxidant activities of litchi (Litchi chinensis Sonn.) polysaccharides extracted by ultra-high pressure. International Journal of Food Science \& Technology, 52(8), 1739-1750. http:// dx.doi.org/10.1111/ijfs.13447.

Geethangili, M., \& Ding, S. T. (2018). A review of the phytochemistry and pharmacology of Phyllanthus urinaria L. Frontiers in Pharmacology, 9, 1109. http://dx.doi.org/10.3389/fphar.2018.01109. PMid:30327602.

Han, Q.-H., Liu, W., Li, H.-Y., He, J.-L., Guo, H., Lin, S., Zhao, L., Chen, H., Liu, Y.-W., Wu, D.-T., Li, S.-Q., \& Qin, W. (2019). Extraction optimization, physicochemical characteristics, and antioxidant activities of polysaccharides from kiwifruit (Actinidia chinensis planch.). Molecules, 24(3), 461-480. http://dx.doi.org/10.3390/ molecules24030461. PMid:30696067.

Hau, D. K., Gambari, R., Wong, R. S., Yuen, M. C., Cheng, G. Y., Tong, C. S., Zhu, G. Y., Leung, A. K., Lai, P. B., Lau, F. Y., Chan, A. K., Wong, W. Y., Kok, S. H., Cheng, C. H., Kan, C. W., Chan, A. S., Chui, C. H., Tang, J. C., \& Fong, D. W. (2009). Phyllanthus urinaria extract attenuates acetaminophen induced hepatotoxicity: involvement of cytochrome P450 CYP2E1. Phytomedicine, 16(8), 751-760. http:// dx.doi.org/10.1016/j.phymed.2009.01.008. PMid:19386480.
Hu, Z., Wang, P., Zhou, H., \& Li, Y. (2018). Extraction, characterization and in vitro antioxidant activity of polysaccharides from Carex meyeriana Kunth using different methods. International Journal of Biological Macromolecules, 120(Pt B), 2155-2164. http://dx.doi. org/10.1016/j.ijbiomac.2018.09.125. PMid:30248430.

Jiang, Y., Yu, J., Li, Y., Wang, L., Hu, L., Zhang, L., \& Zhou, Y. (2019). Extraction and antioxidant activities of polysaccharides from roots of Arctium lappa L. International Journal of Biological Macromolecules, 123, 531-538. http://dx.doi.org/10.1016/j.ijbiomac.2018.11.087. PMid:30439439.

Jing, Y., Gao, Y., Wang, W., Cheng, Y., Lu, P., Ma, C., \& Zhang, Y. (2016). Optimization of the extraction of polysaccharides from tobacco wasteand their biological activities. International Journal of Biological Macromolecules, 91, 188-197. http://dx.doi.org/10.1016/j. ijbiomac.2016.05.069. PMid:27211300.

Lam, P.-L., Kok, S. H.-L., Ho, Y.-W., Wong, R. S.-M., Cheng, G. Y.-M., Cheng, C.-H., Lam, K.-H., Gambari, R., Lee, K. K.-H., \& Chui, C.-H. (2013). A novel green gelatin-agar microencapsulation system with P. urinaria as an improved anti-A. niger model. Carbohydrate Polymers, 92(1), 877-880. http://dx.doi.org/10.1016/j.carbpol.2012.09.080. PMid:23218379.

Li, F., Liu, X., Yu, X., Xu, X., \& Yang, H. (2019). Optimization of the extraction, preliminary characterization, and anti-inflammatory activity of crude polysaccharides from the stems of Trapa quadrispinosa. RSC Advances, 9(39), 22540-22550. http://dx.doi.org/10.1039/ C8RA09994D.

Lin, L., Xie, J., Liu, S., Shen, M., Tang, W., \& Xie, M. (2017). Polysaccharide from Mesona chinensis: Extraction optimization, physicochemical characterizations and antioxidant activities. International Journal of Biological Macromolecules, 99, 665-673. http://dx.doi.org/10.1016/j. ijbiomac.2017.03.040. PMid:28284935.

Lin, S. Y., Wang, C. C., Lu, Y. L., Wu, W. C., \& Hou, W. C. (2008). Antioxidant, anti-semicarbazide-sensitive amine oxidase, and anti-hypertensive activities of geraniin isolated from Phyllanthus urinaria. Food and Chemical Toxicology, 46(7), 2485-2492. http:// dx.doi.org/10.1016/j.fct.2008.04.007. PMid:18495318.

Lin, Y., Zeng, H., Wang, K., Lin, H., Li, P., Huang, Y., Zhou, S., Zhang, W., Chen, C., \& Fan, H. (2019). Microwave-assisted aqueous two-phase extraction of diverse polysaccharides from Lentinus edodes: process optimization, structure characterization and antioxidant activity. International Journal of Biological Macromolecules, 136, 305-315. http://dx.doi.org/10.1016/j.ijbiomac.2019.06.064. PMid:31199973.

Liu, Y., Liao, Y., Wei, S., Zhang, H., \& Wang, X. (2019). Nanoparticles based on sodium alginate and $\beta$-conglycinin: self-assembly and delivery of Phyllanthus urinaria phenolic compounds. Journal of Food Processing and Preservation, 43(1), e13851. http://dx.doi. org/10.1111/jfpp.13851.

Liu, Y., She, X. R., Huang, J. B., Liu, M. C., \& Zhan, M. E. (2018). Ultrasonic-extraction of phenolic compounds from Phyllanthus urinaria: optimization model and antioxidant activity. Food Science and Technology, 38(Suppl. 1), 286-293. http://dx.doi.org/10.1590/1678$457 \times .21617$.

Ma, J. S., Liu, H., Han, C. R., Zeng, S. J., Xu, X. J., Lu, D. J., \& He, H. J. (2020). Extraction, characterization and antioxidant activity of polysaccharide from Pouteria campechiana seed. Carbohydrate Polymers, 229, 115409. http://dx.doi.org/10.1016/j.carbpol.2019.115409. PMid:31826479.

Mediani, A., Abas, F., Khatib, A., Tan, C. P., Ismail, I. S., Shaari, K., Ismail, A., \& Lajis, N. H. (2015). Phytochemical and biological features of Phyllanthus niruri and Phyllanthus urinaria harvested at different growth stages revealed by ${ }^{1} \mathrm{H}$ NMR-based metabolomics. 
Industrial Crops and Products, 77, 602-613. http://dx.doi.org/10.1016/j. indcrop.2015.09.036.

Mo, L., Chen, Y., Li, W., Guo, S., Wang, X., An, H., \& Zhan, Y. (2017). Anti-tumor effects of $(1 \rightarrow 3)-\beta$-d-glucan from Saccharomyces cerevisiae in S180 tumor-bearing mice. International Journal of Biological Macromolecules, 95, 385-392. PMIid, 27838421. http:// dx.doi.org/10.1016/j.ijbiomac.2016.10.106. PMid:27838421.

Nuerxiati, R., Abuduwaili, A., Mutailifu, P., Wubulikasimu, A., Rustamova, N., Jingxue, C., Aisa, H. A., \& Yili, A. (2019). Optimization of ultrasonic-assisted extraction, characterization and biological activities of polysaccharides from Orchis chusua D. Don (Salep). International Journal of Biological Macromolecules, 141, 431-443. http://dx.doi.org/10.1016/j.ijbiomac.2019.08.112. PMid:31445150.

Raza, A., Li, F., Xu, X., \& Tang, J. (2017). Optimization of ultrasonicassisted extraction of antioxidant polysaccharides from the stem of Trapa quadrispinosa using response surface methodology. International Journal of Biological Macromolecules, 94(Pt A), 335-344. http://dx.doi.org/10.1016/j.ijbiomac.2016.10.033. PMid:27751809.

Ru, Y., Chen, X., Wang, J., Guo, L., Lin, Z., Peng, X., \& Qiu, B. (2019). Polysaccharides from Tetrastigma hemsleyanum Diels et Gilg: Extraction optimization, structural characterizations, antioxidant and antihyperlipidemic activities in hyperlipidemic mice. International Journal of Biological Macromolecules, 125, 1033-1041. http://dx.doi. org/10.1016/j.ijbiomac.2018.11.236. PMid:30500505.

Shang, H., Li, R., Wu, H., \& Sun, Z. (2019). Polysaccharides from Trifolium repens $\mathrm{L}$. extracted by different methods and extraction condition optimization. Scientific Reports, 9(1), 6353. http://dx.doi. org/10.1038/s41598-019-42877-5. PMid:31015549.

Tahmouzi, S., \& Ghodsi, M. (2014). Optimum extraction of polysaccharides from motherwort leaf and its antioxidant and antimicrobial activities. Carbohydrate Polymers, 112, 396-403. http://dx.doi.org/10.1016/j. carbpol.2014.06.024. PMid:25129759.

Wang, H., Li, Y., Ren, Z., Cong, Z., Chen, M., Shi, L., Han, X., \& Pei, J. (2018a). Optimization of the microwave-assisted enzymatic extraction of Rosa roxburghii Tratt. polysaccharides using response surface methodology and its antioxidant and a-d-glucosidase inhibitory activity. International Journal of Biological Macromolecules, 112, 473-482. http://dx.doi.org/10.1016/j.ijbiomac.2018.02.003. PMid:29412175.

Wang, J., Hu, S., Nie, S., Yu, Q., \& Xie, M. (2016). Reviews on mechanisms of in vitro antioxidant activity of polysaccharides.
Oxidative Medicine and Cellular Longevity, 2016, 5692852. http:// dx.doi.org/10.1155/2016/5692852. PMid:26682009.

Wang, Y., Xu, Y., Ma, X., Liu, X., Yang, M., Fan, W., Ren, H., Efehi, N., Wang, X., \& Zhu, X. (2018b). Extraction, purification, characterization and antioxidant activities of polysaccharides from Zizyphus jujuba cv. Linzexiaozao. International Journal of Biological Macromolecules, 118(Pt B), 2138-2148. http://dx.doi.org/10.1016/j.ijbiomac.2018.07.059. PMid:30021134.

Xu, Z., Wang, B., Fu, L., Wang, H., Liu, J., Zhou, L., Yuan, M., \& Ding, C. (2019). Optimization extraction, purification and antioxidant activities of polysaccharides from Penthorum Chinense pursh. International Journal of Food Engineering, 15(3-4), 1-11. http:// dx.doi.org/10.1515/ijfe-2018-0152.

Yang, S., Li, Y., Jia, D., Yao, K., \& Liu, W. (2017). The synergy of BoxBehnken designs on the optimization of polysaccharide extraction from mulberry leaves. Industrial Crops and Products, 99, 70-78. http://dx.doi.org/10.1016/j.indcrop.2017.01.024.

Ying, Z., Han, X., \& Li, J. (2011). Ultrasound-assisted extraction of polysaccharides from mulberry leaves. Food Chemistry, 127(3), 1273-1279. http://dx.doi.org/10.1016/j.foodchem.2011.01.083. PMid:25214126.

Zhang, C., Zhou, Y., Sun, Z., Feng, J., \& Wang, Y. (2014). Polysaccharides extraction from Erythirna variegata, chemicalcharacterization and its antioxidant activity. International Journal of Biological Macromolecules, 68, 267-273. http://dx.doi.org/10.1016/j.ijbiomac.2014.05.009. PMid:24832984.

Zhang, Y., Jiang, Z., Wang, L., \& Xu, L. (2017). Extraction optimization, antioxidant, and hypoglycemic activities in vitro of polysaccharides from broccoli byproducts. Journal of Food Biochemistry, 41(5), e12387. http://dx.doi.org/10.1111/jfbc.12387.

Zhao, J. L., Zhang, M., \& Zhou, H. L. (2019). Microwave-assisted extraction, purification, partial characterization, and bioactivity of polysaccharides from panax ginseng. Molecules, 24(8), 1605-1622. http://dx.doi.org/10.3390/molecules24081605. PMid:31018583.

Zheng, Q., Li, W., Zhang, H., Gao, X., \& Tan, S. (2019). Optimizing synchronous extraction and antioxidant activity evaluation of polyphenols and polysaccharides from Yảan Tibetan tea (Camellia sinensis). Food Science \& Nutrition, 8(1), 489-499. http://dx.doi. org/10.1002/fsn3.1331. PMid:31993173. 